\title{
Resilience as pathway diversity: linking systems, individual, and temporal perspectives on resilience
}

\author{
$\underline{\text { Steven J. Lade }}^{1,2}$ Brian H. Walker $^{2,3}$ and L. Jamila Haider $^{1}$
}

\begin{abstract}
Approaches to understanding resilience from psychology and sociology emphasize individuals' agency but obscure systemic factors. Approaches to understanding resilience stemming from ecology emphasize system dynamics such as feedbacks but obscure individuals. Approaches from both psychology and ecology examine the actions or attractors available in the present, but neglect how actions taken now can affect the configuration of the social-ecological system in the future. Here, we propose an extension to resilience theory, which we label "pathway diversity", that links existing individual, systems, and temporal theories of resilience into a common framework. In our theory of pathway diversity, resilience is greater if more actions are currently available and can be maintained or enhanced into the future. Using a stylized model of an agricultural social-ecological system, we show how pathway diversity could deliver a context-sensitive method of assessing resilience and guiding planning. Using a stylized state-and-transition model of a poverty trap, we show how pathway diversity is generally consistent with existing definitions of resilience and can illuminate long-standing questions about normative and descriptive resilience. Our results show that pathway diversity advances both theoretical understanding and practical tools for building resilience.
\end{abstract}

Key Words: agency; agriculture; poverty trap; resilience; systems

\section{INTRODUCTION}

In an age of turbulent social and environmental change, the concept of resilience has grown from origins in ecology (Holling 1973) and psychology (Garmezy 1973) to become one of the most widely used concepts in sustainable development. Calls are frequently made to build resilience in cities (Meerow et al. 2016), communities (Berkes and Ross 2013), and ecosystems (Chapin et al. 2009, Mitchell et al. 2014). A large body of research (Folke 2006, Baggio et al. 2015) studies resilience from multiple disciplinary and interdisciplinary perspectives.

Research on social-ecological systems views resilience as "a system's capacity to cope with shocks and undergo change while retaining essentially the same structure and function" (Walker et al. 2009). Resilience may involve adaptation or even transformation to a different kind of system, in addition to persistence (Folke et al. 2016). Its historically systems-based perspective has emphasized the roles of feedbacks, nonlinearities, and slow and fast variables in generating phenomena such as regime shifts, adaptive cycles, traps, and transformations. This systems view of resilience has been critiqued for failing to deal adequately with the roles of individual actors, and factors such as power relationships that can limit their agency (Hornborg 2009, Cote and Nightingale 2012, Olsson et al. 2015). Although research on traps and transformations (Westley et al. 2013, Boonstra et al. 2016) and political and social drivers of resilience (Schoon et al. 2015) has begun to deal with these factors, there is a strong need for inclusion of agent-oriented approaches to resilience that explicitly incorporate social dimensions of resilience (Brown 2015, Cinner and Barnes 2019).

Existing concepts that take a more agent-oriented approach to social-ecological resilience include response diversity and resilience-as-filtering. Originally an ecological concept (Elmqvist et al. 2003), response diversity states that a community (or ecosystem) with a greater variety of responses to a shock will be more likely to withstand that shock (Leslie and McCabe 2013, Grêt-Regamey et al. 2019). Resilience-as-filtering views resilience as the result of active and passive filtering of old and new practices by actors within a social-ecological system (Haider 2017). However, these existing agent-oriented approaches to resilience are limited in the degree to which they can account for the system feedbacks that have made social-ecological resilience such a powerful concept. For example, a response that enhances resilience in the short term but degrades a social-ecological system's physical or human assets may not be helpful for the longterm resilience of the system. Furthermore, both systems- and agent-oriented perspectives on resilience focus on resilience at a snapshot in time and have limited capacity to analyze how available responses or system attractors change over time.

Finally, despite the popularity of resilience, it can be unclear how to assess it quantitatively or how to use it to guide different policy options. Early metrics of resilience based on distance to a critical threshold (Walker et al. 2004) neither indicate how far from the threshold is desirable nor account for the need for adaptation or transformation in addition to withstanding change. The seven "principles for building resilience" (Biggs et al. 2015) are useful governance guidelines but do not give guidance on specific policy choices and have limited capacity to analyze the roles of specific actors in building or managing resilience. Instead, economic optimization that underplays the risks of shocks or nonlinear change is frequently used to guide decision-making (Barfuss et al. 2018), often undermining resilience (Walker and Salt 2006). Formal definitions of resilience that can guide decision-making are needed to better translate resilience into policy and to challenge economic optimization as the dominant decisionmaking heuristic.

${ }^{1}$ Stockholm Resilience Centre, Stockholm University, Stockholm, Sweden, ${ }^{2}$ Fenner School of Environment and Society, Australian National University, Canberra, Australia, ${ }^{3}$ CSIRO Sustainable Ecosystems, Australia 
Here, we propose a theory of resilience as pathway diversity, where actors have greater resilience if they have access to a higher number of action pathways (Fig. 1). Pathway diversity links (1) systems-oriented perspectives such as feedbacks and regime shifts, (2) agent-oriented perspectives such as response diversity and option space, and (3) temporal perspectives such as pathways, into a common conceptual framework while avoiding a "universal" metric for resilience that is not sensitive to context.

Fig. 1. Pathways and pathway diversity. The diversity of future pathways is constrained and enabled by exogenous and endogenous drivers and endogenous feedbacks.

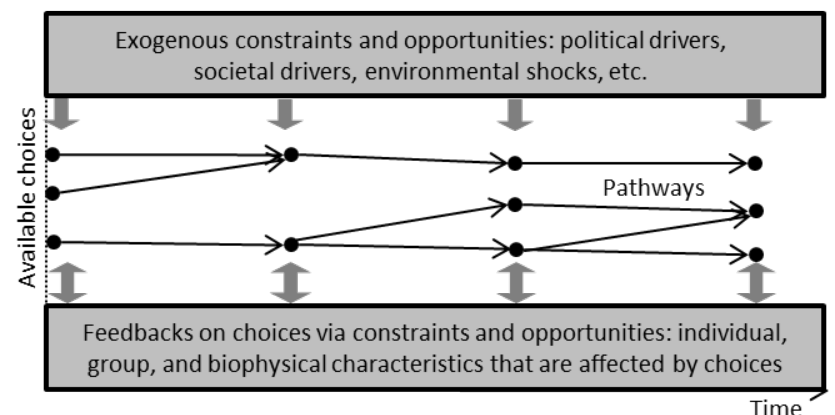

We begin by reviewing current approaches to resilience and identifying their shortcomings that we aim to address with pathway diversity. We introduce and explain the components of the pathway diversity framework. We then illustrate how pathway diversity could be applied to qualitative and quantitative empirical research using the tools of adaptation pathways and causal entropy. Our focus here is primarily theoretical, laying the methodological basis for future empirical applications.

\section{CURRENT APPROACHES TO RESILIENCE}

Current understandings of resilience have developed from separate origins in psychology (Garmezy 1973) and ecology (Holling 1973) (Table 1), which, in turn, built on uses of the term in materials science tracing back to the 19th century (Tredgold 1818, Mallet 1856). Different communities of research and practice maintain, at times, markedly different conceptions and operationalizations of resilience (Baggio et al. 2015, Fraccascia et al. 2018, Lade and Peterson 2019).

\section{Ecological resilience}

In ecology, resilience was originally defined as a "measure of the persistence of systems and of their ability to absorb change and disturbance and still maintain the same relationships between populations or state variables" (Holling 1973). A wide variety of definitions are now used in ecological research, and it is not our goal to review them all. Definitions involving the ability to resist and recover from disturbance (Ingrisch and Bahn 2018) are common and are often visualized using the ball and cup diagram (Fig. 2A). Common metrics for measuring resilience include distance to a threshold or, more recently, the variance of time series (Scheffer et al. 2009).

\section{Social-ecological resilience}

The recognition that understanding ecological resilience requires understanding the behavior of humans involved with those ecosystems triggered the development of the field of socialecological systems research (Berkes et al. 2002, Sterk et al. 2017) and the study of social-ecological resilience. A key advance was that resilience involves not only persistence, but also adaptation in response to disturbances, as well as transformation when necessary (Walker et al. 2004, Folke et al. 2010). Social-ecological resilience is also conceptually the broadest of the strands of resilience, seeking to include ecological dynamics, individual human behavior, and collective human behavior within its analysis (Ostrom 2009).

Fig. 2. State-of-the-art resilience theoretical frameworks. (A) Ball-and-cup diagrams displaying a regime shift. Stable states occur at the bottom of the landscape's "valleys". Reproduced from Gunderson (2000). (B) Expanding the ball-and-cup diagram to trajectories of ecosystem services. Reproduced from Enfors (2013). (C) The S-curve of economic poverty trap models. A fixed point occurs when future assets is the same as current assets, that is, when the solid line crosses the dashed diagonal line; this S-curve shows a stable "poor" and "not-poor "states separated by an unstable state. Modified from Lade et al. (2017).

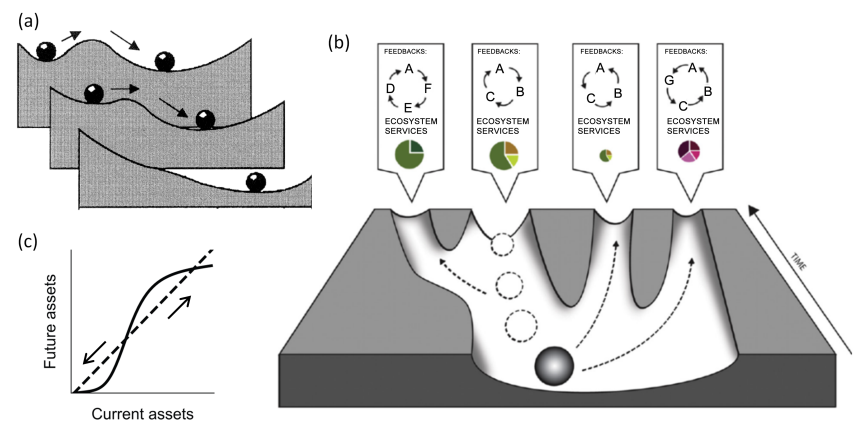

Apart from the triad of resilience as persistence, adaptability, and transformability (Walker et al. 2004), few general conceptual frameworks of what resilience is have been developed to match the concept's transition from ecological to social-ecological systems. A common critique of research on social-ecological resilience from a social science perspective is that it often uses an ontology of systems thinking, inherited from ecological resilience, that has limited its ability to incorporate individual action and constraints on that action such as inequality, power, and agency (Cote and Nightingale 2012, Brown 2014, Olsson et al. 2015). Although some recent resilience work has addressed these research gaps, for example, on transformative agency in socialecological systems (Westley et al. 2013), social-ecological traps (Boonstra et al. 2016), sense of place (Masterson et al. 2017), political drivers of resilience (Schoon et al. 2015), and social drivers of resilience (Robards et al. 2011), agency is still largely absent from frameworks and theories of resilience. An approach that combines systems-oriented and agent-oriented perspectives of resilience would allow agency and power to be dealt with more explicitly (Brown 2015).

From an implementation perspective, current approaches to social-ecological resilience emphasize the complex adaptive systems nature of social-ecological systems and have limited 
Table 1. Summary of resilience definitions and metrics from various fields. The definitions given are representative only; within each field, there may be strong debate and a large diversity of views on resilience.

\begin{tabular}{|c|c|c|c|}
\hline Field & Representative definition & Metrics & Weaknesses \\
\hline Ecology & $\begin{array}{l}\text { "the persistence of systems and ... their ability } \\
\text { to absorb change and disturbance" (Holling } \\
\text { 1973) }\end{array}$ & $\begin{array}{l}\text { Distance to threshold, size of basin } \\
\text { of attraction, eigenvalue, variance }\end{array}$ & $\begin{array}{l}\text { Originally did not recognize that } \\
\text { resilience sometimes requires adaptation } \\
\text { or transformation }\end{array}$ \\
\hline $\begin{array}{l}\text { Social-ecological } \\
\text { systems }\end{array}$ & $\begin{array}{l}\text { "a measure of a system's capacity to cope } \\
\text { with shocks and undergo change while } \\
\text { retaining essentially the same structure and } \\
\text { function" (Walker et al. 2009, Folke et al. } \\
\text { 2016) }\end{array}$ & $\begin{array}{l}\text { "Resilience principles" (Biggs et al. } \\
\text { 2015) offer guidelines for policy }\end{array}$ & $\begin{array}{l}\text { General concept that can be difficult to } \\
\text { implement }\end{array}$ \\
\hline Psychology & $\begin{array}{l}\text { "ability to bounce back from negative } \\
\text { emotional experiences" (Tugade et al. 2004) }\end{array}$ & $\begin{array}{l}\text { Sets of individual criteria } \\
\text { (Rodriguez-Llanes et al. 2013) }\end{array}$ & $\begin{array}{l}\text { Attributes resilience to the individual; } \\
\text { does not recognize systemic factors }\end{array}$ \\
\hline Development & $\begin{array}{l}\text { "capacity of a person, household or other } \\
\text { aggregate unit to avoid poverty in the face of } \\
\text { various stressors and in the wake of myriad } \\
\text { shocks" (Barrett and Constas 2014) }\end{array}$ & $\begin{array}{l}\text { Sets of indicators of individual } \\
\text { capabilities }\end{array}$ & $\begin{array}{l}\text { Metrics are not context sensitive (Levine } \\
\text { 2014); a single resilience measure may } \\
\text { block deeper understanding of system } \\
\text { dynamics (Quinlan et al. 2016) }\end{array}$ \\
\hline
\end{tabular}

capacity to provide guidance when confronted with a specific policy choice. General guidelines have been offered for how to build resilience (Biggs et al. 2015), global limits have been identified (Steffen et al. 2015), and resilience assessments help understand how a particular social-ecological system operates (Sellberg et al. 2015). There is understandable reluctance to develop universal measures of resilience given that the features that make social-ecological systems resilient may vary widely (Quinlan et al. 2016) and such a measure could lead to top-down control that actually undermines resilience (Cox 2016). In any resilience analysis, the "whom, what, when, where, and why" of resilience must also be considered (Meerow and Newell 2019). However, the lack of a clear approach to quantifying socialecological resilience leaves economic optimization as the dominant quantifiable policy goal. An approach to quantifying and optimizing resilience that delivers on the largely unrealized potential for optimization methods to be used in conjunction with resilience (Fischer et al. 2009), and which still accounts for context dependence, could be used to challenge economic optimization.

\section{Psychological resilience}

The concept of resilience has as long a history in psychology (Garmezy 1973), as in ecology (Holling 1973). Psychological resilience research studies the ability of individuals to withstand stress, generally attributing lack of resilience to characteristics of the individual rather than systemic factors. More recently, research into social resilience (Adger 2000) has studied the ability of communities or other groups to withstand disturbance, better taking systemic and contextual factors into account. Psychological, cultural, and emotional dimensions of environmental change are increasingly recognized in sustainability science as fundamental in shaping strategies of persistence, adaptation, or transformation in the face of uncertainty (Brown et al. 2019). Many of the tools for measuring social resilience have been developed by researchers and practitioners for resilience in development, which we now describe.

\section{Resilience in development}

Resilience is highly prominent in discussions of international development and poverty alleviation agendas in academia, policy, and practice (Brown 2015). Development programming frequently sets "building resilience" as an explicit goal of interventions. In the international policy arena, resilience is a central concept in frameworks such as the Sustainable Development Goals. Despite the widespread use of the term, there are markedly different understandings about what it is, how it can be assessed (Quinlan et al. 2016), and how it can be built (Béné et al. 2014).

Intensive effort to measure resilience has led to the development of criteria-based resilience metrics (Cinner et al. 2015, FAO 2016). These lists help to incorporate a diversity of views on resilience. However, they are so broad that they can be used to justify a wide range of interventions; they neglect the complex interrelationships that comprise poverty; and they fail to be context sensitive, that is, the factors that contribute to resilience in one location may be very different from the factors that contribute to resilience elsewhere (Levine 2014).

\section{Pathways conceptions of resilience}

The challenge of navigating along and between different "pathways to resilience" or "pathways to sustainability" is a common problem framing in sustainable development. We introduce three examples of this framing.

First, the "pathways approach" of the STEPS centre (Leach et al. 2010) studies how a particular development pathway can be envisioned and enacted, and importantly, how the framing of a particular pathway constructs the core dimensions, relations, and behaviors of a system. While the STEPS pathways approach has foundations in complex adaptive systems thinking, the central driving force of change is differential power co-produced by discursive and material aspects of the system (West et al. 2014). As opposed to social-ecological resilience approaches, which have a foundation in more positivist-oriented epistemologies, the STEPS pathway approach is driven by a more constructivist inquiry, in which the character of a system is negotiated through framing (and by the virtue of including some things, others are excluded). These differences in understanding systems and the role of human agency in defining them have led to debates that constructivism may curtail urgent action (see, for example, the 
debate between Johan Rockström and Melissa Leach, as documented by Brown 2015:22). Indeed, the question of framing brings into focus the normativity of resilience and sustainability and the power that these concepts have come to imbue (Cretney 2014, Walker 2020). The space between these different approaches on pathways to resilience have since been narrowed through the promotion and acceptance that equity and sustainability must go hand-in-hand for sustainable and fair futures (Leach et al. 2018).

Second, the adaptation pathways framework can be used to study sequencing and potential lock-in of adaptation decisions (Haasnoot et al. 2013). It was developed to aid in exploring and prioritizing adaptation actions in futures when options are available for only limited time periods (Haasnoot et al. 2013). It illustrates which alternative actions are available at each point in time from the current state of the social-ecological system. Wise et al. (2014) identified that adaptation pathways in practice often demonstrate dynamics characteristic of complex systems, such as path dependency, whereby a decision affects the availability of future actions and the occurence of maladaptive spaces that limit future actions and transformative change when a decision is taken to change the social-ecological system substantively. Although the adaptation pathways framework can be used as a tool for building resilience, it does not make any statements about the connection between the diversity of pathways and resilience.

Third, attempts have been made to extend the ball-and-cup model of resilience with a temporal dimension along metaphorical pathways (Enfors 2013, Steffen et al. 2018; Fig. 2B) in a threedimensional representation that builds on Waddington's (1957) representations of epigenetic landscapes. These graphical heuristics have limited analytical power, however.

Often the implicit view in a pathways perspective is that different pathways lead to different outcomes for resilience, and an appropriate pathway should be chosen and molded carefully. However, this view does not account for the relationship between the number or diversity of different pathways and resilience outcomes. Here, we develop a theory based on a pathways perspective that can incorporate the insights of systems- and more individual-oriented approaches of resilience through analyzing the diversity of available pathways.

\section{RESILIENCE AS PATHWAY DIVERSITY}

We propose a theory of resilience as pathway diversity, the diversity of future pathways available to an agent or agents (Box 1). In this theory, higher pathway diversity leads to higher resilience. We use a specific understanding of a pathway as a sequence of actions made by an actor or set of actors (Box 1). Decisions that promote resilience, under this theory, are those that maintain existing available actions or improve the array of actions available to actors in the social-ecological system now and into the future.

Here, we elaborate on the key components of pathway diversity: constraints limit available actions, greater diversity of actions means greater resilience, but the consequences of an action on future availability of actions along a pathway must be taken into account. Through these elements, pathway diversity provides a framing that can link individual and systems theories of resilience.

\section{Box 1: Definitions}

Pathway: A temporal sequence of actions taken by an agent or agents and the associated changes in the social-ecological system in which they are embedded. An agent could be an individual, household, community, or other group. In practice, assessment of pathways will need to be truncated at some time horizon.

Pathway diversity: The diversity of pathways available to an agent or agents.

\section{Constraints on available actions: contributions from individual perspectives on resilience}

Individual or agent-centric perspectives of resilience are necessary to understand the factors that enable and constrain different actions and the pathways to which those actions lead. Available pathways will depend on the structural constraints and opportunities that actors face, and their actions will depend on their knowledge and motivation. For example, power relationships could lead to an actor's available actions being suppressed or restricted, or alternatively could allow an actor to access previously unavailable actions; the knowledge or physical skills possessed by a person may limit their available choices; habit or preference may constrain available actions; and other available resources such as financial or natural capital may also constrain their actions. Many concepts and frameworks could be used to study these factors, of which we next give some examples. Although consideration of the constraints on agency must be a part of any pathway diversity analysis, we do not here favor any particular analytical framework.

The traps framework of Boonstra et al. (2016) distinguishes between the desires, abilities, and opportunities for actors to respond to a trap. Abilities and opportunities provide, respectively, internal and external constraints on an actor's access to actions, whereas desires enable the actor's capacity to make use of that access. Similarly, the values-rules-knowledge framework (Gorddard et al. 2016) distinguishes between the values that determine how likely an actor is to make use of an available action, the rules-in-use and rules-in-form that constrain or enable the available actions, and the knowledge that an actor uses to assess which actions are available.

In development studies, Sen's (2001) capabilities approach famously laid out the argument that resources (inputs) must be converted into valuable functionings, which depends on a person's physical ability, social context, and environmental constraints, among other factors. A person's capability is a set of diverse valuable functionings, but the functionings that a person achieves are those that are actually selected by the individual. Our theorization of pathways diversity therefore only includes pathways on which people actually have the capability to act.

The sustainable livelihoods framework expresses constraints on action through five interlinked capitals (Scoones 1998, 2009, Serrat 2017): financial capital, natural capital, human capital, social capital, and physical capital. Levels of these capitals are influenced by environmental, economic, and political factors, and 
the levels of these capitals, in turn, constrain which livelihood options are available. Livelihoods approaches have been noted as being ripe for integration with resilience concepts (Tanner et al. 2015).

\section{Connecting diversity with resilience}

We connect available actions to resilience by claiming that actors are more resilient if they have a greater diversity of actions available or, equivalently, a larger "option space" (EnforsKautsky et al. 2018). Diversity is an intuitive surrogate for resilience: the more different things a system has, the better its capacity to respond to disturbances or change (Biggs et al. 2015). For example, biodiversity is believed to be important for ecosystem resilience. Response diversity (Elmqvist et al. 2003), which has also been applied to social-ecological systems (Leslie and McCabe 2013, Grêt-Regamey et al. 2019), identifies diversity of initial response capabilities with resilience. Resilience is improved if multiple entities perform the same function (functional redundancy) and is even further improved if they respond differently to shocks or stresses (response diversity). If a particular disturbance removes one or more entities in a functional group, the function persists in the short term as long as one or more of the entities in that functional group remain. However, it does not ensure long-term viability of that group. Furthermore, while response diversity counts the diversity of species (Elmqvist et al. 2003) or actors (Leslie and McCabe 2013, Grêt-Regamey et al. 2019) according to their responses, pathway diversity could arise from the different future pathways available to a single agent. Diversity in the pathways of energy flow through an ecosystem also has long been proposed to promote stability (MacArthur 1955); here, we also identity diversity of pathways with resilience but do not discuss energy flows.

Although there are many ways to measure diversity, such measures generally involve some combination of variety, balance, and disparity (Stirling 2007). A simple initial approach for pathways diversity would be simply to count the number of pathways (variety) out to some specified time horizon. We use this approach in the applied investigation of pathway diversity in the next section. In the section thereafter, we offer a quantitative measure of pathway diversity that allows weights of different pathways to be incorporated (combination of variety and balance). This approach would recognize that pathways that are in principle possible but in practice unlikely to be accessed, due to the constraints on actions discussed above or due to changes in these constraints, do not significantly contribute to resilience. There may also be substantial qualitative disparities between pathways, for example, a pathway that leads to business as usual compared to a pathway that leads to adaptation or transformation, but we have not yet built a disparity metric into a measure of pathway diversity.

Furthermore, in the example applications we present below, we consider only the diversity of pathways associated with the decisions of a single actor. In the case of multiple actors, the diversity of these actors' attributes could play a key role, for example, a diversity of problem solving methods (Hong and Page 2004, Page 2007), diverse knowledge or perspectives of system properties or dynamics (Arlinghaus and Krause 2013, Cronin and Weingart 2019), functionally diverse cognitive abilities (Baggio et al. 2019), or diverse behavior (Schill et al. 2019).
Feedbacks from actions: contributions from systems perspectives on resilience

If an action reduces the actions available to an actor in the future, for example, by running down their natural or financial capital, then that action does not contribute to that actor's resilience (Abel et al. 2016). It is thus important to emphasize that we define resilience not in terms of the diversity of available actions, but rather as the diversity of the available pathways of actions. Available pathways could therefore be enabled or constrained both by feedbacks involving attributes of the agent (such as their abilities or desires), their environment (such as their biophysical environment or their relationships with other agents), or external drivers (such as the political, economic, social, and biophysical contexts of the actors; Fig. 1). As in structuration theory (Giddens 1986), pathways result from the interplay of systemic feedbacks with individual agency.

In systems language, assessing pathways rather than only initial actions allows the consequences of actions to feed back through their effects on the social-ecological system to affect the actor's future availability of actions. A pathways perspective thus incorporates the concept of feedback, which is a core element of systems perspectives on resilience. In the section Theoretical investigation of pathway diversity: poverty traps below, we show that pathway diversity is consistent with other systems resilience concepts such as traps and regime shifts. A pathway perspective also moves beyond static understandings of the configuration of a social-ecological system such as the ball-and-cup diagram (Fig. $2 \mathrm{~A}$ ) by allowing the possible options of actors in the system to change over time (Fig. 2B). Our approach to pathways is consistent with Sen's (2001) vision of capabilities whereby simply having more options is not useful if those options do not lead to an increase in the functionings available to a person (Wells 2012).

\section{APPLIED INVESTIGATION OF PATHWAY DIVERSITY: AGRICULTURAL RESILIENCE PLANNING}

We now illustrate how pathway diversity can be assessed and used to guide decision-making using a stylized model of a farmer in an industrialized, water-stressed society. The stylized model we use here is purely graphical, based on a number of assumptions that greatly simplify reality, not based on any specific case, and is clearly not intended for prediction or for policy. We use this deliberately simplistic representation of reality to succinctly illustrate pathway diversity.

Identification of pathways

We assume that the farmer has the following alternative livelihoods:

- Single crop variety monoculture: This farming strategy is highly economically productive but highly susceptible to disease.

- Multiple crop varieties, in which several varieties of the same kind of crop are grown: This strategy means that if disease or financial shocks reduce the viability of one crop, the farmer has other crops from which to choose.

- Mixed cropping, in which several different crops are grown: The farmer can readily convert from growing mixed crops to single crops or single varieties, but not back again. 
- Cattle farming and cropping: The farmer can readily convert to cattle farming or cropping, but not back again without government support for diversification.

- Cattle only: We assume that all crops will fail in moderate drought, but cattle farming can be maintained. However, we also assume in this model that in good conditions, cattle farming is less economically productive than cropping. In times of severe drought, cattle farming will also fail unless supported by drought-relief subsidies.

- Tourism: If the farmer retains sufficient funds, they can invest in and switch to a livelihood from tourism. Once the farmer has switched to tourism (for example, by selling all farming infrastructure and installing accommodations), the farmer cannot readily switch back to cattle or cropping. Tourism is only sustainable if tourism demand is sufficiently strong.

- Exit: The farmer can choose to exit from this set of livelihoods at any time. We do not consider what happens to the farmer after exit. If the farmer persists with nonviable cropping, cattle farming, or tourism for more than two years, degradation of farmland or loss of financial assets force the farmer to exit.

In the system specification "resilience of what, to what, for whom" commonly associated with resilience thinking (Carpenter et al. 2001, Elmqvist 2014), the "of what" is the farmer-farm socialecological system and the "for whom" is the farmer. Regarding "to what", the idea of maintaining multiple future pathways is to promote resilience against unspecified future threats, that is, general resilience. In this section, we test this general resilience against a specific pattern of various external drivers or "to whats" (Fig. 3A). We graphically represented the resulting pathways available to the farmer in a form based on the adaptation pathways framework (Fig. 3B).

Although we use the adaptation pathways framework as a visualization tool, pathway diversity delivers conceptual and operational advances beyond adaptation pathways by associating pathway diversity with resilience in a way that can be computed. The adaptation pathways framework is about staying within a set of viable system states and not crossing into a maladaptive space, whereas pathway diversity is about the number of choices for staying within that viable set.

In the particular pattern of drivers that we chose to illustrate this model, disease first causes failure of the single crop strategy. A beef price crash causes exit from the cattle-only strategy, but we assume a mixed cattle and cropping strategy can be maintained via income from cropping. A moderate drought causes exit from all cropping strategies. This event is followed by a severe drought, which would also have caused exit from cattle farming were it not for government drought relief. After the end of the drought, diversification assistance can help farmers return to a mixed cattle and cropping strategy. Tourism is also vulnerable to shocks, with a reduction in tourism demand leading to exit from tourism. In this example, we do not explicitly consider limitations on the knowledge or other capacities of the farmer to identify and act on these different options, though this will be a critically important factor in any empirical case study.
Fig. 3. Pathway diversity analysis of agricultural decisionmaking. (A) Drivers that influence the available options. (B) Available pathways. (C) Calculation of pathway diversity for each action at every point in time. The actions of maximum pathway diversity (numbers) in each year are bolded.

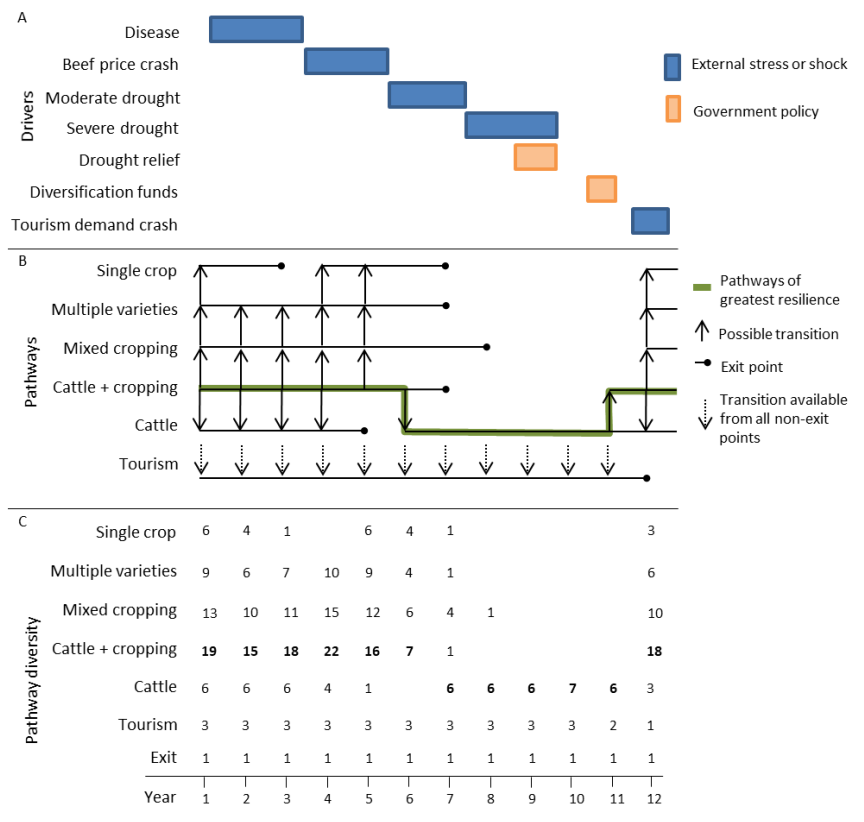

We can see in our adaptation pathways (Fig. 3B) many of the complex systems phenomena identified by Wise et al. (2014). If cropping is chosen during drought, the farmer becomes lockedin to this livelihood because of feedbacks from declining natural and financial capital and is eventually forced to exit. Lock-in is a form of path dependence (Mahoney 2000, Page 2006) in which future decision-making options become substantially narrowed (Allison and Hobbs 2004). We characterize switching between cropping strategies (such as single and multiple varieties) as adaptation. A transition to tourism, however, is a transformation because it involves fundamental reorganization of the farmer's activity and the farm's infrastructure that cannot readily be reversed.

\section{Pathway diversity and resilience: guiding decision-making}

We identified the pathways of greatest resilience (green highlights, Fig. 3B) in this toy model based on the map of pathways, but not explicitly considering pathway diversity, as follows. Initially, the most resilient livelihood strategy for the farmer is mixed cattle and cropping because mixed pathways generally provide the greatest range of future options (Meert et al. 2005). When a moderate drought occurs, however, cropping becomes unviable in this model. Maintaining a cropping strategy would lead to lockin and then exit within two years (years 6-7). The strategy of highest resilience, which allows the farmer to stay on their land, is to switch to cattle farming only once the drought hits and while the option is still available (year 6). Drought relief helps the farmer withstand severe drought (year 9), while diversification support allows the farmer to return to a high-resilience mixed cropping and cattle strategy. This pathway allows the farmer to deal with 
known threats while also leaving as many options as possible open for unknown threats, that is, to maintain both specific and general resilience (Folke et al. 2010). We should note here that this measure of resilience is at the farm level, and resilience across scales would require additional considerations. For example, we are not here making claims about the resilience of cattle production or consumption at a global food system level.

We now demonstrate that pathway diversity predicts pathways of greatest resilience that are consistent with the intuitive understanding above. For all livelihood strategies at all points in time, we assumed that the farmer had full knowledge of future pathways up to two years in the future. We calculated pathway diversity by counting the number of distinct action pathways starting from that livelihood strategy out to two years in the future. For example, if the farmer is engaged in mixed cropping coming in to year 2, they have 10 decision pathways available for the coming two years (years 2-3): Mixed cropping-Mixed cropping; Mixed cropping-Multiple varieties; Multiple varieties-Multiple varieties; Mixed cropping-Tourism; Mixed cropping-Exit; Multiple varieties-Tourism; Multiple varieties-Exit; TourismTourism; Tourism-Exit; and Exit-Exit. Each year's actions with maximum pathway diversity (Fig. 3C, bolded entries) correspond exactly with the intuitively chosen pathways of greatest resilience (Fig. 3B).

We have shown that pathway diversity offers an operational definition of resilience that is readily computed from an adaptation pathways diagram. Whereas conventional approaches to resilience recognize the need for persistence, adaptation, and transformation (Folke et al. 2016), a pathway diversity approach recommended a transformation at exactly the same time as intuitive understandings of resilience. Pathway diversity as implemented here could therefore guide decision-making and policy-making to build resilience.

The toy model we have used here has many limitations. First, each of the livelihoods considered here and the ease of switching between them are likely subject to many more factors. Transformation to tourism as livelihood will require specific knowledge and skills and may require substantial financial capital. Second, full knowledge of pathways up to two years in the future is fully known by farmers. In practice, decisions are constrained by uncertainty about the future trajectories of specific drivers and deep uncertainty about unknown future pressures. An operational version of this framework will have to be probabilistic, with probabilities assigned to possible future drivers. Finally, we study farming decision-making and its effects only at a local scale; for example, cattle farming may not be an option that builds resilience in larger food systems (Willett et al. 2019). Further research is needed that will apply pathway diversity to more realistic situations or models that better reflect the dynamics of real social-ecological systems and the uncertainties associated with decision-making. This research could include embedding a pathway diversity analysis within a participatory resilience assessment and planning process. Building resilience against unknown future shocks comprises a form of decisionmaking under deep uncertainty (Kwakkel and Haasnoot 2019).

\section{THEORETICAL INVESTIGATION OF PATHWAY DIVERSITY: POVERTY TRAPS}

The agricultural example in the previous section investigated how a pathway diversity framework could be used to assess resilience empirically and to guide decision-making. We now explore assessment of resilience within a stylized mathematical model. A systematic mathematical operationalization of pathway diversity would allow it to be compared formally with existing systems approaches with resilience, and also opens the possibility for a quantitative assessment of resilience as pathway diversity in mathematical models. In this section, we offer causal entropy as a metric of pathway diversity and apply it to a toy model of a poverty trap.

\section{Causal entropy: mathematical implementation of pathway diversity}

A likely candidate for implementation is the mathematical formalism of causal entropy (Wissner-Gross and Freer 2013). Causal entropy is a measure of the diversity of future pathways that are accessible from a specified starting state within a specified time horizon. The causal entropy of state $x_{\mathrm{i}}$ in a discrete state space with time horizon $\tau$ is

$$
S\left(x_{i}, \tau\right)=-\sum_{j} \sum_{k} P\left(x_{j k}, t+\tau \mid x_{i}, t\right) \log P\left(x_{j k}, t+\tau \mid x_{i}, t\right)
$$

where $j$ and $k$ denote the different pathways available to endogenous and exogenous degrees of freedom and are the probabilities of the system taking the different pathways denoted by $j$ and $k$. It is causal because all pathways causally connected to an initial state $x_{\mathrm{i}}$ are considered, and it is entropy because it measures the unpredictability of which pathway will be taken. This approach to diversity can be conceptualized as a combination of variety and balance (Stirling 2007).

We caution that the use of the term entropy here is purely in a descriptive sense, as a measure of the diversity of pathways, as it is used in information theory. Physical laws associated with thermodynamic entropy, such as the second law of thermodynamics stating that entropy must increase in a closed system, have no relevance here. Confusion between the different varieties of entropy used in different branches of physics has led to substantial misuse and misunderstanding (Kovalev 2016).

Causal entropy was first widely used in astrophysics (Brustein and Veneziano 2000). Wissner-Gross and Freer (2013) applied causal entropy to mathematical models intended to reproduce intelligence tests involving tool use. They controversially claimed that intelligent agents, or complex systems in general, tend to follow a path generated by causal entropic forcing. Again, we avoid any such prescriptive ambitions, but rather use causal entropy as a descriptive measure of pathway diversity.

The mathematical definition of causal entropy (Eq. 1) allows for two sources of variability: endogenous and exogenous to the system under study. In the exogenous case, the freedom of any actors within the system is ignored, and variability emerges from the possible actions of agents or entities external to the system. "Agent-less" models of resilience, such as distance to a threshold, are compatible with the exogenous view: While there are decisions being made that affect the distance to a threshold, these decisions are not explicitly incorporated in the model. The endogenous case, however, provides an opportunity for agency to be incorporated into a model setting. In the endogenous case, agency can be attributed to actors internal to the system. Constructing a model that displays causal entropy thus requires the possible actions of agents within the system, such as navigating away from a 
threshold, to be made explicit. Limitations to an individual's agency could be specified according to factors, including power relationships, norms, available assets, and individual motivation.

\section{Descriptive and prescriptive resilience: pathway diversity analysis of a poverty trap}

We illustrate the potential of causal entropy as a measure of resilience using a simple state-and-transition model (Westoby et al. 1989, Bestelmeyer et al. 2017) of a poverty trap (Fig. 4A). The model consists of three states: an initial state A; a state B from which recovery to A usually occurs; and a third state $C$, reachable from $B$ with low probability, from which recovery to A and B is possible but unlikely. $\mathrm{C}$ corresponds to a poverty trap, A corresponds to a "not-poor" state with greater freedom, and the transition $\mathrm{B}$ to $\mathrm{C}$ corresponds to a regime shift into the poverty trap.

We calculated the causal entropy of each of the states A, B, and $\mathrm{C}$ out to a time horizon of 10 transitions by brute force: mapping all possible pathways of length 10 and probabilities associated with all those paths. The results show that the trapped state $\mathrm{C}$ has the lowest causal entropy because there are few pathways available from that state, whereas state A has highest causal entropy (Fig. $4 \mathrm{~B})$. The causal entropy of A and B are even higher when we modified the model to include multiple pathways for returning to A from B and for remaining at A (Fig. 4B, dotted lines).

Resilience as pathway diversity might therefore be able to shed light on long-standing discussions about descriptive and prescriptive versions of resilience (Béné et al. 2014, Olsson et al. 2015). Resilience researchers usually maintain that resilience is a descriptive concept. For example, under the conventional association of resilience with persistence, both the trapped state $\mathrm{C}$ and the not-poor state $\mathrm{A}$ would have high resilience because they are easily able to maintain (and $\mathrm{C}$ would have the highest resilience), but the resilience of A would be labelled a "good" resilience, whereas the resilience of $\mathrm{C}$ would be labelled a "bad" resilience (Béné et al. 2014). Outside academia, however, resilience is often used normatively or prescriptively (Walker 2020): resilience is always "good"; therefore, A would be high resilience but C low resilience. High "bad" resilience is sometimes referred to as rigidity (Holling et al. 2002).

Interpreting resilience as pathway diversity, however, gives A as the highest resilience state and $\mathrm{C}$ as the lowest resilience state. Pathway diversity is thus a descriptive measure of resilience that, unlike stability metrics, assesses a poverty trap as a state of low resilience. Therefore, pathway diversity could be seen as an implementation of more recent social-ecological approaches to resilience, for example, that define resilience as the capacity to adapt or transform (Folke et al. 2016) or in terms of general resilience (Folke et al. 2010, Carpenter et al. 2012), which would also assess the trapped state $\mathrm{C}$ as low resilience.

We thus find that pathway diversity is consistent with existing understandings of resilience-as-persistence that associate proximity to a regime shift as a reduction in resilience, but also matches with more modern notions of resilience-as-capacity-toadapt or -transform that associate a poverty trap with low resilience. We also show that resilience as capacity to recover from shocks is enhanced if there are more options available to deal with different kinds of shocks.
Fig. 4. Pathway diversity of a poverty trap. (A) State-andtransition model showing a state $\mathrm{A}$, which recovers from a transition to state $\mathrm{B}$ with high probability $(0.8)$, but if a transition to $\mathrm{C}$ occurs, then recovery is highly unlikely (0.05). The intention, as illustrated in the ball-and-cup diagram, is that $\mathrm{C}$ corresponds to a trapped state of high persistence; $\mathrm{A}$ is a more desirable stable state with lower persistence, and B is an unstable intermediate state. (B) Causal entropy for the different states as a function of the time horizon. A is the state of highest causal entropy, followed by B, then the trapped state C. Where there are two recovery paths from $\mathrm{B}$ to $\mathrm{A}$ as well as two paths to maintain A, the causal entropy of states A and B are even higher (dotted lines, A2-C2 in figure legend).

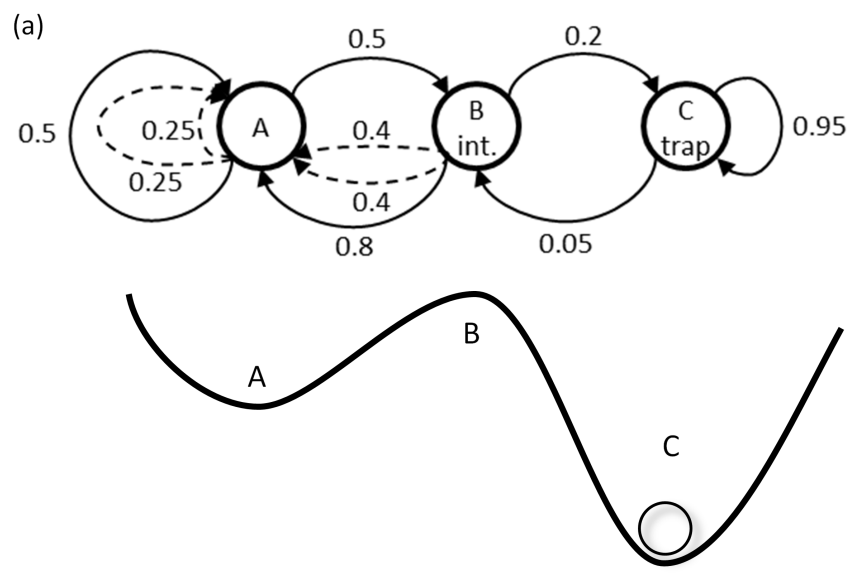

(b)

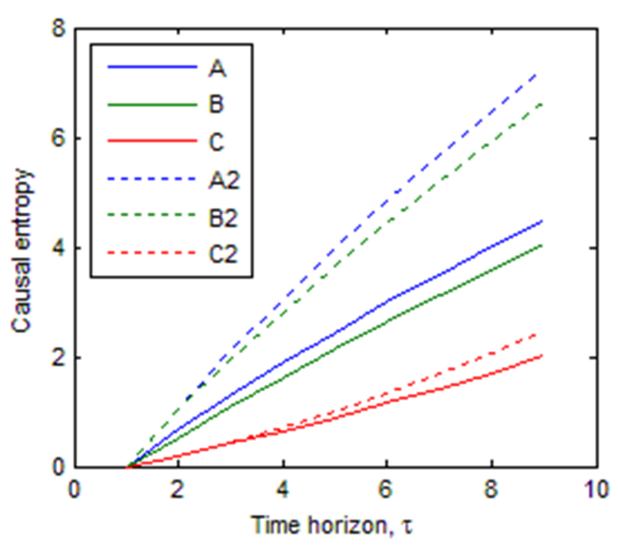

Maximizing pathway diversity in a model setting could offer an alternative policy goal to economic optimization that underplays the risks of shocks or nonlinear change. Although fully maximizing pathway diversity may also be undesirable, as we argue below, it could nevertheless be used to illuminate alternative policy goals. The final policy may be a choice between economic optimization and maximum pathway diversity, depending on stakeholder priorities. 


\section{DISCUSSION}

We take this opportunity to anticipate potential critiques of pathway diversity as resilience. First, in introducing our theory of resilience as pathway diversity, we do not aim to replace any existing theories or tools for resilience. Rather, we see pathway diversity as a complementary concept that can unite previously disparate approaches to resilience and guide decision-making for resilience. For example, we have shown that pathway diversity can guide decision-making in a way that: distinguishes when it is better to adapt or transform, links individual constraints on decisionmaking with systemic feedbacks, is consistent with classical resilience concepts associating regime shifts with a loss of resilience, and is consistent with more modern understandings of a poverty trap as a state of high persistence (rigidity) but low general resilience (Folke et al. 2010). Guidelines for resilience such as the seven principles for building resilience (Biggs et al. 2015) contribute factors that improve the number and accessibility of pathways. Resilience assessments contribute to revealing key components and critical thresholds at which certain options lead to significant impacts on the social-ecological system (Walker et al. 2009, Sellberg et al. 2015, 2018, Enfors-Kautsky et al. 2018) and key assets or capacities that contribute to a system's resilience (Constas et al. 2014, FAO 2016).

Second, pathway diversity is a quantification of resilience and therefore could be used to design policies to maintain or increase resilience; indeed, we used it to calculate the pathways of greatest resilience in the stylized agricultural examples. Resilience researchers are justifiably wary of general metrics of resilience, for example, because they could lead to top-down control to the detriment of the system that is being managed (Cox 2016), or out of suspicion that any general metric exists that could be usefully applied across the wide variety of contexts and systems in which resilience is used (Quinlan et al. 2016). To these concerns, we note that to assess pathway diversity requires a full description (or as full as is available) of the social-ecological system, including alternative options and the consequences of options expressed via feedbacks. It requires making assumptions of the description of the social-ecological system transparent, and requires reflexivity on the part of the researcher to reassess continually the adequacy of the description. Any assessment of pathway diversity will thus be highly specific to the system being assessed. Although we must remain attentive to risks associated with quantifying resilience, pathway diversity presents an opportunity to capitalize on the possible synergies between optimization approaches and resilience (Fischer et al. 2009) within the factors that constrain resilience in a specific context.

Third, we claim that pathway diversity as resilience is descriptive, not normative. In the poverty trap model, we showed that the pathway diversity of a poverty trap is low, in line with understandings of a poverty trap as a situation of low resilience. Poverty traps are also undesirable, and therefore, low resilience aligns with low desirability in this case. High pathway diversity, however, is not necessarily desirable, depending on whose pathway diversity is high. For example, high pathway diversity and thereby high resilience of a tyrant would be undesirable for much of the country's population (while the pathway diversity of the members of that population might be low). Furthermore, high pathway diversity might not be helpful if the available pathways do not help with a specific shock (such as a market collapse) that occurs.
Lastly, although resilience as pathway diversity generally increases when there are more actions available, it does not promote maximizing available actions at any cost. If some actions are harmful to the broader social-ecological system in that they decrease the availability of future actions, then these actions do not contribute to pathway diversity and resilience. Likewise, if the cost of maintaining availability of options is accounted for, then maintaining a large array of options may decrease resilience by reducing the financial capital needed to access those actions. For example, increasing complexity is commonly theorized to contribute to decreased resilience of societies (Tainter 1988, Cumming and Peterson 2017). Resilience could then be seen as the task of balancing navigation along a desirable path with maintaining a large "search space" of alternative options (Prokopenko and Gershenson 2014).

There remains substantial work to develop tools for application of pathway diversity both in quantitative modeling and in resilience planning. In the analyses above, we used a computationally intensive approach to compute causal entropy as pathway diversity. For models with more alternative states, in particular, models with a continuous state space, more efficient methods will be needed to compute and to choose pathways that maximize pathway diversity. Random sampling methods are one possibility. However, any method will need to be suitable for the high-dimensional distributions formed by the pathways as they branch apart, for example, the Metropolis-Hastings algorithm (Chib and Greenberg 1995). Furthermore, in cases such as the examples above, in which the available options at a point in time form Markov chains that depend only on the current state of the system plus external drivers, it may be possible to exploit this Markov property to update pathway diversity estimates sequentially in time.

Further development of this pathway diversity approach to analyzing resilience calls for four kinds of activities. First, whether pathway diversity is a useful framing for resilience should be tested in resilience planning workshops. Second, more computationally efficient methods of calculating and maximizing pathway diversity need to be developed. Third, methods to deal with uncertainties in future trajectories of external drivers, future social-ecological dynamics, and current and future options of actors will be needed if pathway diversity is to be a practical tool for decision-making. Fourth, models of pathway diversity should be developed based on empirical cases.

\section{CONCLUSION}

We have proposed a theory of resilience called pathway diversity that views resilience as the diversity of current actions and capabilities to maintain or enhance the diversity of options in the future. Pathway diversity links existing individual and systemic theories of resilience by viewing available actions as subject to social-ecological feedbacks from past decisions. Pathway diversity moves beyond stable-state representations of social-ecological systems such as the ball-and-cup to represent, and to focus on, how the available options and trajectories change over time. We illustrated how pathway diversity could be used in resilience planning, and we showed that pathway diversity matched an intuitive prediction of the pathway of highest resilience among adaptation and transformation options. We also illustrated how pathway diversity can be used to analyze quantitative models, 
where we showed that pathway diversity is consistent with and builds upon existing approaches to resilience. There remains substantial work to refine the pathway diversity concept and further develop tools for its application. Our work demonstrates, however, that pathway diversity contributes an important and useful advance toward uniting the diverse definitions of resilience and to delivering a new tool for translating the resilience concept into practice.

Responses to this article can be read online at: http://www.ecologyandsociety.org/issues/responses. php/11760

\section{Acknowledgments:}

The research leading to these results has received funding from the Swedish Research Council Formas (grant 2014-589).

\section{Data Availability Statement:}

The code that supports the findings of this study is openly available in Open Science Framework at https://doi.org/10.17605/OSF. IO/6G8YM.

\section{LITERATURE CITED}

Abel, N., R. M. Wise, M. J. Colloff, B. H. Walker, J. R. A. Butler, P. Ryan, C. Norman, A. Langston, J. M. Anderies, R. Gorddard, M. Dunlop, and D. O'Connell. 2016. Building resilient pathways to transformation when "no one is in charge": insights from Australia's Murray-Darling Basin. Ecology and Society 21(2):23. http://dx.doi.org/10.5751/ES-08422-210223

Adger, W. N. 2000. Social and ecological resilience: Are they related? Progress in Human Geography 24(3):347-364. https://doi. org/10.1191/030913200701540465

Allison, H. E., and R. J. Hobbs. 2004. Resilience, adaptive capacity, and the "lock-in trap" of the Western Australian agricultural region. Ecology and Society 9(1):3. https://doi. org/10.5751/ES-00641-090103

Arlinghaus, R., and J. Krause. 2013. Wisdom of the crowd and natural resource management. Trends in Ecology and Evolution 28(1):8-11. https://doi.org/10.1016/j.tree.2012.10.009

Baggio, J. A., K. Brown, and D. Hellebrandt. 2015. Boundary object or bridging concept? A citation network analysis of resilience. Ecology and Society 20(2):2. https://doi.org/10.5751/ ES-07484-200202

Baggio, J. A., J. Freeman, T. R. Coyle, T. T. Nguyen, D. Hancock, K. E. Elpers, S. Nabity, H. J. F. Dengah II, and D. Pillow. 2019. The importance of cognitive diversity for sustaining the commons. Nature Communications 10:875. https://doi.org/10.1038/ $\underline{\text { s41467-019-08549-8 }}$

Barfuss, W., J. F. Donges, S. J. Lade, and J. Kurths. 2018. When optimization for governing human-environment tipping elements is neither sustainable nor safe. Nature Communications 9:2354. https://doi.org/10.1038/s41467-018-04738-z
Barrett, C. B., and M. A. Constas. 2014. Toward a theory of resilience for international development applications. Proceedings of the National Academy of Sciences 111(40):14625-14630. https:// dx.doi.org/10.1073/pnas.1320880111

Béné, C., A. Newsham, M. Davies, M. Ulrichs, and R. GodfreyWood. 2014. Resilience, poverty and development. Journal of International Development 26(5):598-623. https://doi.org/10.1002/ jid.2992

Berkes, F., J. Colding, and C. Folke. 2002. Navigating socialecological systems: building resilience for complexity and change. Cambridge University Press, Cambridge, UK. https://doi. org/10.1017/CBO9780511541957

Berkes, F., and H. Ross. 2013. Community resilience: toward an integrated approach. Society and Natural Resources 26(1):5-20. https://doi.org/10.1080/08941920.2012.736605

Bestelmeyer, B. T., A. Ash, J. R. Brown, B. Densambuu, M. Fernández-Giménez, J. Johanson, M. Levi, D. Lopez, R. Peinetti, L. Rumpff, and P. Shaver. 2017. State and transition models: theory, applications, and challenges. Pages 303-345 in D. D. Briske, editor. Rangeland systems: processes, management and challenges. Springer, Cham, Switzerland. https://doi. org/10.1007/978-3-319-46709-2_9

Biggs, R., M. Schlüter, and M. L. Schoon, editors. 2015. Principles for building resilience: sustaining ecosystem services in socialecological systems. Cambridge University Press, Cambridge, UK. https://doi.org/10.1017/CBO9781316014240

Boonstra, W. J., E. Björkvik, L. J. Haider, and V. Masterson. 2016. Human responses to social-ecological traps. Sustainability Science 11(6):877-889. https://doi.org/10.1007/s11625-016-0397$\underline{x}$

Brown, K. 2014. Global environmental change I: a social turn for resilience? Progress in Human Geography 38(1):107-117. https:// doi.org/10.1177/0309132513498837

Brown, K. 2015. Resilience, development and global change. Routledge, London, UK. https://doi.org/10.4324/9780203498095

Brown, K., W. N. Adger, P. Devine-Wright, J. M. Anderies, S. Barr, F. Bousquet, C. Butler, L. Evans, N. Marshall, and T. Quinn. 2019. Empathy, place and identity interactions for sustainability. Global Environmental Change 56:11-17. https://doi.org/10.1016/j. gloenvcha.2019.03.003

Brustein, R., and G. Veneziano. 2000. Causal entropy bound for a spacelike region. Physical Review Letters 84(25):5695-5698. https://doi.org/10.1103/PhysRevLett.84.5695

Carpenter, S. R., K. J. Arrow, S. Barrett, R. Biggs, W. A. Brock, A.-S. Crépin, G. Engström, C. Folke, T. P. Hughes, N. Kautsky, C.-Z. Li, G. McCarney, K. Meng, K.-G. Mäler, S. Polasky, M. Scheffer, J. Shogren, T. Sterner, J. R. Vincent, B. Walker, A. Xepapadeas, and A. de Zeeuw. 2012. General resilience to cope with extreme events. Sustainability 4(12):3248-3259. https://doi. org/10.3390/su4123248

Carpenter, S., B. Walker, J. M. Anderies, and N. Abel. 2001. From metaphor to measurement: resilience of what to what? Ecosystems 4(8):765-781. https://doi.org/10.1007/s10021-001-0045-9 
Chapin, F. S. III, G. P. Kofinas, and C. Folke. 2009. Principles of ecosystem stewardship: resilience-based natural resource management in a changing world. Springer, New York, New York, USA. https://doi.org/10.1007/978-0-387-73033-2

Chib, S., and E. Greenberg. 1995. Understanding the MetropolisHastings algorithm. American Statistician 49(4):327-335. https:// doi.org/10.1080/00031305.1995.10476177

Cinner, J. E., and M. L. Barnes. 2019. Social dimensions of resilience in social-ecological systems. One Earth 1(1):51-56. https://doi.org/10.1016/j.oneear.2019.08.003

Cinner, J. E., C. Huchery, C. C. Hicks, T. M. Daw, N. Marshall, A. Wamukota, and E. H. Allison. 2015. Changes in adaptive capacity of Kenyan fishing communities. Nature Climate Change 5(9):872-876. https://doi.org/10.1038/nclimate2690

Constas, M. A., T. R. Frankenberger, J. Hoddinott, N. Mock, D. Romano, C. Béné, and D. Maxwell. 2014. A common analytical model for resilience measurement: causal framework and methodological options. Technical Series 2. Food Security Information Network, World Food Programme, Rome, Italy. [online] URL: https://www.fsnnetwork.org/common-analyticalmodel-resilience-measurement-causal-framework-and-methodologicaloptions

Cote, M., and A. J. Nightingale. 2012. Resilience thinking meets social theory: situating social change in socio-ecological systems (SES) research. Progress in Human Geography 36(4):475-489. https://doi.org/10.1177/0309132511425708

Cox, M. 2016. The pathology of command and control: a formal synthesis. Ecology and Society 21(3):33. https://doi.org/10.5751/ ES-08698-210333

Cretney, R. 2014. Resilience for whom? Emerging critical geographies of socio-ecological resilience. Geography Compass 8 (9):627-640. https://doi.org/10.1111/gec3.12154

Cronin, M. A., and L. R. Weingart. 2019. Conflict across representational gaps: threats to and opportunities for improved communication. Proceedings of the National Academy of Sciences 116(16):7642-7649. https://doi.org/10.1073/pnas. 1805866116

Cumming, G. S., and G. D. Peterson. 2017. Unifying research on social-ecological resilience and collapse. Trends in Ecology and Evolution 32(9):695-713. https://doi.org/10.1016/j.tree.2017.06.014

Elmqvist, T. 2014. Urban resilience thinking. Solutions Journal 5 (5):26-30. [online] URL: https://www.thesolutionsjournal.com/ article/urban-resilience-thinking/

Elmqvist, T., C. Folke, M. Nyström, G. Peterson, J. Bengtsson, B. Walker, and J. Norberg. 2003. Response diversity, ecosystem change, and resilience. Frontiers in Ecology and the Environment 1(9):488-494. https://doi.org/10.1890/1540-9295(2003)001[0488: RDECAR]2.0.CO;2

Enfors, E. 2013. Social-ecological traps and transformations in dryland agro-ecosystems: using water system innovations to change the trajectory of development. Global Environmental Change 23(1):51-60. https://doi.org/10.1016/j.gloenvcha.2012.10.007

Enfors-Kautsky, E., P. Ryan, A. Quinlan, and L. Järnberg. 2018. Wayfinder: a resilience guide for navigating toward sustainable futures. Stockholm Resilience Center, Stockholm University, Stockholm, Sweden. [online] URL: https://graid.earth/wpcontent/uploads/2018/04/Wayfinder-folder-4-sid W.pdf

Fischer, J., G. D. Peterson, T. A. Gardner, L. J. Gordon, I. Fazey, T. Elmqvist, A. Felton, C. Folke, and S. Dovers. 2009. Integrating resilience thinking and optimisation for conservation. Trends in Ecology and Evolution 24(10):549-554. https://doi.org/10.1016/j. tree.2009.03.020

Folke, C. 2006. Resilience: the emergence of a perspective for social-ecological systems analyses. Global Environmental Change 16(3):253-267. https://doi.org/10.1016/j.gloenvcha.2006.04.002

Folke, C., R. Biggs, A. V. Norström, B. Reyers, and J. Rockström. 2016. Social-ecological resilience and biosphere-based sustainability science. Ecology and Society 21(3):41. https://doi.org/10.5751/ ES-08748-210341

Folke, C., S. R. Carpenter, B. Walker, M. Scheffer, T. Chapin, and J. Rockström. 2010. Resilience thinking: integrating resilience, adaptability and transformability. Ecology and Society 15(4):20. https://doi.org/10.5751/ES-03610-150420

Food and Agriculture Organization (FAO). 2016. RIMA-II: resilience index measurement and analysis II. FAO, Rome, Italy. [online] URL: http://www.fao.org/emergencies/resources/documents/ resources-detail/en/c/416587/

Fraccascia, L., I. Giannoccaro, and V. Albino. 2018. Resilience of complex systems: state of the art and directions for future research. Complexity 2018:3421529. https://doi.org/10.1155/2018/3421529

Garmezy, N. 1973. Competence and adaptation in adult schizophrenic patients and children at risk. Pages 163-204 in S. R. Dean, editor. Schizophrenia: the first ten Dean Award lectures. MSS Information Corporation, New York, New York, USA.

Giddens, A. 1986. The constitution of society: outline of the theory of structuration. Polity Press, Cambridge, UK.

Gorddard, R., M. J. Colloff, R. M. Wise, D. Ware, and M. Dunlop. 2016. Values, rules and knowledge: adaptation as change in the decision context. Environmental Science and Policy 57:60-69. https://doi.org/10.1016/j.envsci.2015.12.004

Grêt-Regamey, A., S. H. Huber, and R. Huber. 2019. Actors' diversity and the resilience of social-ecological systems to global change. Nature Sustainability 2:290-297. https://doi.org/10.1038/ s41893-019-0236-Z

Haasnoot, M., J. H. Kwakkel, W. E. Walker, and J. ter Maat. 2013. Dynamic adaptive policy pathways: a method for crafting robust decisions for a deeply uncertain world. Global Environmental Change 23(2):485-498. https://doi.org/10.1016/j.gloenvcha.2012.12.006

Haider, L. J. 2017. Development and resilience: re-thinking poverty and intervention in biocultural landscapes. Dissertation. Stockholm University, Stockholm, Sweden. [online] URL: https://www.stockholmresilience.org/publications/artiklar/2017-10-02development-and-resilience-re-thinking-poverty-and-interventionin-biocultural-landscapes.html

Holling, C. S. 1973. Resilience and stability of ecological systems. Annual Review of Ecology and Systematics 4:1-23. https://doi. org/10.1146/annurev.es.04.110173.000245 
Holling, C. S., L. H. Gunderson, and G. D. Peterson. 2002. Sustainability and panarchies. Pages 63-102 in L. H. Gunderson and C. S. Holling, editors. Panarchy: understanding transformations in human and natural systems. Island Press, Washington, D.C., USA.

Hong, L., and S. E. Page. 2004. Groups of diverse problem solvers can outperform groups of high-ability problem solvers. Proceedings of the National Academy of Sciences 101 (46):16385-16389. https://doi.org/10.1073/pnas.0403723101

Hornborg, A. 2009. Zero-sum world: challenges in conceptualizing environmental load displacement and ecologically unequal exchange in the world-system. International Journal of Comparative Sociology 50(3-4):237-262. https://doi. org/10.1177/0020715209105141

Ingrisch, J., and M. Bahn. 2018. Towards a comparable quantification of resilience. Trends in Ecology and Evolution 33 (4):251-259. https://doi.org/10.1016/j.tree.2018.01.013

Kovalev, A. V. 2016. Misuse of thermodynamic entropy in economics. Energy 100:129-136. https://doi.org/10.1016/j. energy.2016.01.071

Kwakkel, J. H., and M. Haasnoot. 2019. Supporting DMDU: a taxonomy of approaches and tools. Pages 355-374 in V. A. W. J. Marchau, W. E. Walker, P. J. T. M. Bloemen, and S. W. Popper, editors. Decision making under deep uncertainty: from theory to practice. Springer, Cham, Switzerland. https://doi. org/10.1007/978-3-030-05252-2 15

Lade, S. J., and G. D. Peterson. 2019. Comment on "Resilience of complex systems: state of the art and directions for future research." Complexity 2019:6343545. https://doi. org/10.1155/2019/6343545

Leach, M., B. Reyers, X. Bai, E. S. Brondizio, C. Cook, S. Díaz, G. Espindola, M. Scobie, M. Stafford-Smith, and S. M. Subramanian. 2018. Equity and sustainability in the Anthropocene: a social-ecological systems perspective on their intertwined futures. Global Sustainability 1:e13. https://doi. org/10.1017/sus.2018.12

Leach, M., I. Scoones, and A. Stirling. 2010. Dynamic sustainabilities: technology, environment, social justice. Routledge, London, UK. https://doi.org/10.4324/9781849775069

Leslie, P., and J. T. McCabe. 2013. Response diversity and resilience in social-ecological systems. Current Anthropology 54 (2):114-143. https://doi.org/10.1086/669563

Levine, S. 2014. Assessing resilience: why quantification misses the point. Humanitarian Policy Group working paper. Overseas Development Institute, London, UK. [online] URL: https://www. odi.org/sites/odi.org.uk/files/odi-assets/publications-opinion-files/9049. pdf

MacArthur, R. 1955. Fluctuations of animal populations and a measure of community stability. Ecology 36(3):533-536. https:// doi.org/10.2307/1929601

Mahoney, J. 2000. Path dependence in historical sociology. Theory and Society 29(4):507-548. [online] URL: https://www.jstor.org/ stable/3108585
Mallet, R. 1856. On the physical conditions involved in the construction of artillery: with an investigation of the relative and absolute values of the materials principally employed, and of some hitherto unexplained causes of the destruction of cannon in service. Longmans, Brown, Green, Longmans, and Roberts, London, UK.

Masterson, V. A., R. C. Stedman, J. Enqvist, M. Tengö, M. Giusti, D. Wahl, and U. Svedin. 2017. The contribution of sense of place to social-ecological systems research: a review and research agenda. Ecology and Society 22(1):49. https://doi.org/10.5751/ ES-08872-220149

Meerow, S., and J. P. Newell. 2019. Urban resilience for whom, what, when, where, and why? Urban Geography 40(3):309-329. https://doi.org/10.1080/02723638.2016.1206395

Meerow, S., J. P. Newell, and M. Stults. 2016. Defining urban resilience: a review. Landscape and Urban Planning 147:38-49. https://doi.org/10.1016/j.landurbplan.2015.11.011

Meert, H., G. Van Huylenbroeck, T. Vernimmen, M. Bourgeois, and E. van Hecke. 2005. Farm household survival strategies and diversification on marginal farms. Journal of Rural Studies 21 (1):81-97. https://doi.org/10.1016/j.jrurstud.2004.08.007

Mitchell, M., R. Griffith, P. Ryan, G. Walkerden, B. Walker, V. A. Brown, and S. Robinson. 2014. Applying resilience thinking to natural resource management through a "planning-by-doing" framework. Society and Natural Resources 27(3):299-314. https:// doi.org/10.1080/08941920.2013.861556

Olsson, L., A. Jerneck, H. Thoren, J. Persson, and D. O'Byrne. 2015. Why resilience is unappealing to social science: theoretical and empirical investigations of the scientific use of resilience Science Advances 1(4):e1400217. https://doi.org/10.1126/sciadv.1400217

Ostrom, E. 2009. A general framework for analyzing sustainability of social-ecological systems. Science 325:419-422. https://doi.org/10.1126/science.1172133

Page, S. E. 2006. Path dependence. Quarterly Journal of Political Science 1(1):87-115. https://doi.org/10.1561/100.00000006

Page, S. E. 2007. Making the difference: applying a logic of diversity. Academy of Management Perspectives 21(4):6-20. https://doi.org/10.5465/amp.2007.27895335

Prokopenko, M., and C. Gershenson. 2014. Entropy methods in guided self-organisation. Entropy 16(10):5232-5241. https://doi. org/10.3390/e16105232

Quinlan, A. E., M. Berbés-Blázquez, L. J. Haider, and G. D. Peterson. 2016. Measuring and assessing resilience: broadening understanding through multiple disciplinary perspectives. Journal of Applied Ecology 53(3):677-687. https://doi.org/10.1111/1365-$\underline{2664.12550}$

Robards, M. D., M. L. Schoon, C. L. Meek, and N. L. Engle. 2011. The importance of social drivers in the resilient provision of ecosystem services. Global Environmental Change 21 (2):522-529. https://doi.org/10.1016/j.gloenvcha.2010.12.004

Rodriguez-Llanes, J. M., F. Vos, and D. Guha-Sapir. 2013. Measuring psychological resilience to disasters: are evidencebased indicators an achievable goal? Environmental Health 12 
(1):115. https://ehjournal.biomedcentral.com/articles/10.1186/1476-069X-12-115

Scheffer, M., J. Bascompte, W. A. Brock, V. Brovkin, S. R. Carpenter, V. Dakos, H. Held, E. H. van Nes, M. Rietkerk, and G. Sugihara. 2009. Early-warning signals for critical transitions. Nature 461:53-59. https://doi.org/10.1038/nature08227

Schill, C., J. M. Anderies, T. Lindahl, C. Folke, S. Polasky, J. C. Cárdenas, A.-S. Crépin, M. A. Janssen, J. Norberg, and M. Schlüter. 2019. A more dynamic understanding of human behaviour for the Anthropocene. Nature Sustainability 2:1075-1082. https://doi.org/10.1038/s41893-019-0419-7

Schoon, M. L., M. D. Robards, K. Brown, N. Engle, C. L. Meek, and R. Biggs. 2015. Politics and the resilience of ecosystem services. Pages 32-49 in R. Biggs, M. Schlüter, and M. L. Schoon, editors. Principles for building resilience: sustaining ecosystem services in social-ecological systems. Cambridge University Press, Cambridge, UK. https://doi.org/10.1017/CBO9781316014240.003

Scoones, I. 1998. Sustainable rural livelihoods: a framework for analysis. IDS Working Papers 72. Institute of Development Studies, Brighton, UK. [online] URL: https://www.ids.ac.uk/ publications/sustainable-rural-livelihoods-a-framework-for-analysis/

Scoones, I. 2009. Livelihoods perspectives and rural development. Journal of Peasant Studies 36(1):171-196. https://doi. org/10.1080/03066150902820503

Sellberg, M. M., P. Ryan, S. T. Borgström, A. V. Norström, and G. D. Peterson. 2018. From resilience thinking to resilience planning: lessons from practice. Journal of Environmental Management 217:906-918. https://doi.org/10.1016/j.jenvman.2018.04.012

Sellberg, M. M., C. Wilkinson, and G. D. Peterson. 2015. Resilience assessment: a useful approach to navigate urban sustainability challenges. Ecology and Society 20(1):43. https:// doi.org/10.5751/ES-07258-200143

Sen, A. 2001. Development as freedom. Oxford University Press, Oxford, UK.

Serrat, O. 2017. Knowledge solutions: tools, methods, and approaches to drive organizational performance. Springer, Singapore. https://doi.org/10.1007/978-981-10-0983-9 5

Steffen, W., K. Richardson, J. Rockström, S. E. Cornell, I. Fetzer, E. M. Bennett, R. Biggs, S. R. Carpenter, W. de Vries, C. A. de Wit, C. Folke, D. Gerten, J. Heinke, G. M. Mace, L. M. Persson, V. Ramanathan, B. Reyers, and S. Sörlin. 2015. Planetary boundaries: guiding human development on a changing planet. Science 347:1259855. https://doi.org/10.1126/science.1259855

Steffen, W., J. Rockström, K. Richardson, T. M. Lenton, C. Folke, D. Liverman, C. P. Summerhayes, A. D. Barnosky, S. E. Cornell, M. Crucifix, J. F. Donges, I. Fetzer, S. J. Lade, M. Scheffer, R. Winkelmann, and H. J. Schellnhuber. 2018. Trajectories of the Earth system in the Anthropocene. Proceedings of the National Academy of Sciences 115(33):8252-8259. https://doi.org/10.1073/ pnas. 1810141115

Sterk, M., I. A. van de Leemput, and E. T. H. M. Peeters. 2017. How to conceptualize and operationalize resilience in socioecological systems? Current Opinion in Environmental Sustainability 28:108-113. https://doi.org/10.1016/j.cosust.2017.09.003
Stirling, A. 2007. A general framework for analysing diversity in science, technology and society. Journal of the Royal Society Interface 4(15):707-719. https://doi.org/10.1098/rsif.2007.0213

Tainter, J. A. 1988. The collapse of complex societies. Cambridge University Press, Cambridge, UK.

Tanner, T., D. Lewis, D. Wrathall, R. Bronen, N. Cradock-Henry, S. Huq, C. Lawless, R. Nawrotzki, V. Prasad, M. A. Rahman, R. Alaniz, K. King, K. McNamara, M. Nadiruzzaman, S. HenlyShepard, and F. Thomalla. 2015. Livelihood resilience in the face of climate change. Nature Climate Change 5(1):23-26. https://doi. org/10.1038/nclimate2431

Tredgold, T. 1818. XXXVII. On the transverse strength and resilience of timber. Philosophical Magazine 51(239):214-216. https://doi.org/10.1080/14786441808637536

Tugade, M. M., B. L. Fredrickson, and L. Feldman Barrett. 2004. Psychological resilience and positive emotional granularity: examining the benefits of positive emotions on coping and health. Journal of Personality 72(6):1161-1190. https://dx.doi.org/10.1111/ j.1467-6494.2004.00294.X

Waddington, C. H. 1957. The strategy of the genes: a discussion of some aspects of theoretical biology. Allen and Unwin, London, UK.

Walker, B. H. 2020. Resilience: what it is and is not. Ecology and Society 25(2):11. https://doi.org/10.5751/ES-11647-250211

Walker, B. H., N. Abel, J. M. Anderies, and P. Ryan. 2009. Resilience, adaptability, and transformability in the GoulburnBroken Catchment, Australia. Ecology and Society 14(1):12. https://doi.org/10.5751/ES-02824-140112

Walker, B., C. S. Holling, S. R. Carpenter, and A. Kinzig. 2004. Resilience, adaptability and transformability in social-ecological systems. Ecology and Society 9(2):5. https://doi.org/10.5751/ ES-00650-090205

Walker, B., and D. Salt. 2006. Resilience thinking: sustaining ecosystems and people in a changing world. Island Press, Washington, D.C., USA.

Wells, T. 2012. Sen's capability approach. in J. Fieser and B. Dowden, editors. Internet Encyclopedia of Philosophy. Internet Encyclopedia of Philosophy, Martin, Tennessee, USA. [online] URL: https://iep.utm.edu/sen-cap/

West, S., J. Haider, H. Sinare, and T. Karpouzoglou. 2014. Beyond divides: prospects for synergy between resilience and pathways approaches to sustainability. STEPS Working Paper 65. STEPS Centre, Brighton, UK. [online] URL: https://steps-centre.org/wpcontent/uploads/Resilience-and-Pathways.pdf

Westley, F. R., O. Tjornbo, L. Schultz, P. Olsson, C. Folke, B. Crona, and Ö. Bodin. 2013. A theory of transformative agency in linked social-ecological systems. Ecology and Society 18(3):27. https://doi.org/10.5751/ES-05072-180327

Westoby, M., B. Walker, and I. Noy-Meir. 1989. Opportunistic management for rangelands not at equilibrium. Journal of Range Management 42(4):266-274. https://doi.org/10.2307/3899492

Willett, W., J. Rockström, B. Loken, M. Springmann, T. Lang, S. Vermeulen, T. Garnett, D. Tilman, F. DeClerck, A. Wood, M. 
Jonell, M. Clark, L. J. Gordon, J. Fanzo, C. Hawkes, R. Zurayk, J. A. Rivera, W. De Vries, L. M. Sibanda, A. Afshin, A. Chaudhary, M. Herrero, R. Agustina, F. Branca, A. Lartey, S. Fan, B. Crona, E. Fox, V. Bignet, M. Troell, T. Lindahl, S. Singh, S. E. Cornell, K. S. Reddy, S. Narain, S. Nishtar, and C. J. L. Murray. 2019. Food in the Anthropocene: the EAT-Lancet Commission on healthy diets from sustainable food systems. Lancet 393(10170):447-492. https://doi.org/10.1016/S0140-6736 (18) $31788-4$

Wise, R. M., I. Fazey, M. Stafford Smith, S. E. Park, H. C. Eakin, E. R. M. A. Van Garderen, and B. Campbell. 2014. Reconceptualising adaptation to climate change as part of pathways of change and response. Global Environmental Change 28:325-336. https://doi.org/10.1016/j.gloenvcha.2013.12.002

Wissner-Gross, A. D., and C. E. Freer. 2013. Causal entropic forces. Physical Review Letters 110(16):168702. https://doi. org/10.1103/PhysRevLett.110.168702 